\title{
Review
}

\section{Influence of sterilization procedures on the physical and mechanical properties of rotating endodontic instruments: a systematic review and network meta-analysis}

\author{
Mario Dioguardi ${ }^{1, *}$, Claudia Arena ${ }^{1}$, Diego Sovereto ${ }^{1}$, Riccardo Aiuto ${ }^{2}$, Luigi Laino ${ }^{3}$, \\ Gaetano Illuzzi $^{1}$, Enrica Laneve ${ }^{1}$, Bruna Raddato ${ }^{1}$, Vito Carlo Alberto Caponio ${ }^{1}$, \\ Antonio Dioguardi ${ }^{4}$, Khrystyna Zhurakivska ${ }^{1}$, Giuseppe Troiano ${ }^{1}$, Lorenzo Lo Muzio ${ }^{1}$ \\ ${ }^{1}$ Department of Clinical and Experimental Medicine, University of Foggia, 71122 Foggia, Italy, ${ }^{2}$ Department of \\ Biomedical, Surgical, and Dental Science, University of Milan, 20122 Milan, Italy, ${ }^{3}$ Multidisciplinary Department of \\ Medical-Surgical and Odontostomatological Specialties, University of Campania "Luigi Vanvitelli", 80121 Naples, Italy, \\ ${ }^{4}$ U.S.C.A. "Unità Speciali di Continuità Assistenziale” Troia 2, ASL “Azienda Sanitaria Locale” Foggia Troia, Italy
}

\section{TABLE OF CONTENTS}

\author{
1. Abstract \\ 2. Introduction \\ 3. Materials and methods \\ 4. Results \\ 5. Discussion
}

5.1 Cyclic fatigue

5.2 Deformations and torsional fatigue

5.3 Corrosion, topographic and surface alterations

5.4 Cutting efficiency

\section{Conclusions}

7. Author contributions

8. Ethics approval and consent to participate

9. Acknowledgment

10. Funding

11. Conflict of interest

12. References

\section{Abstract}

The fracture of endodontic instruments inside the canal represents a problem that is not always easy to solve. The reutilization of endodontic instruments after sterilization procedures raises the question of how these processes affect their physical and mechanical properties. Alterations can involve the surface of the instruments, as well as their cutting effectiveness, shape and resistance to torsional and cyclic fatigue. The methodology adopted for this systematic review followed the PRISMA guidelines for systematic reviews. The following search terms were used in PubMed and Scopus: "endodontic sterilization”, "endodontic autoclave”, "cyclic fatigue”, "torsional”, “cutting efficiency”, "sterilization", "surface characteristics" and "corrosion". After the screening phase, the application of exclusion criteria and the removal of duplicates, 51 studies were identified and divided into four outcomes: cyclic fatigue; deformation and torsional fatigue; corrosion or surface alterations; and cutting efficiency. Our study of the scientific literature highlights disagreements between studies on these effects. After autoclaving, instruments exhibit a reduction in the cutting efficiency, but NiTi alloy instruments have an improved resistance to cyclic and torsional fatigue.

\section{Introduction}

Over time, manufacturers have progressively perfected methods for the production of endodontic instruments for scouting, pre-flaring [1], preparing the glide path and shaping the endodontic canal [2]. Every endodontic file with a cutting capacity can also be employed for shaping. Here, the term "shaping step" refers to the shaping of the coronal, medium and apical parts following the scouting, pre-flaring and glide path steps [3]. 
The main steps of endodontic treatment are scouting, pre-flaring, glide path production, canal shaping and canal finishing, and each step requires an instrument that has different features that correspond to different physical and mechanical characteristics [4].

The sterilization process includes several phases: pre-sterilization, drying, packaging, heat sterilization and storage of the sterile material [5].

Pre-sterilization is the disinfection, decontamination and cleaning of dental instruments. This phase involves immersing the instruments in decontaminating and disinfecting liquids or cleansing them with washer-disinfectors. Decontamination reduces the microbial load on endodontic instruments, while cleansing removes organic and inorganic residues (to avoid the removal of debris by hand brushing, the use of ultrasonic trays is recommended) [6].

The subsequent phases involve the rinsing, drying and packaging of instruments, followed by heat sterilization (autoclave at 134 degrees at 2 atmospheres) to eliminate spores. The last phase is the storage of the instruments.

Other sterilization procedures after the presterilization phase include glass bead sterilization or treatment with $2 \%$ glutaraldehyde (glutaraldehyde was used for high-level disinfection instead of sterilization but is not recommended because of its toxicity) [7].

An important limit to the reuse of endodontic instruments after sterilization lies in the inability to perfectly clean the blades from the debris created following the canal shaping phase [8]; the removal of debris by manual cleaning or with the help of ultrasonic trays does not allow to remove all debris of an organic and inorganic nature. And among these the prions which represent one of the contaminants that can resist decontamination procedures and are only partially inactivated and denatured at the temperatures reached by autoclaves used in dentistry; remember that prions are responsible for spongiform encephalopathy disease in humans [9-12].

Walker et al. [13] in 2007 they described the theoretical possibility of transmission of the pathology through prions through dental and endodontic procedures, indicating however low the risk of transmission [13-15]. Contamination by prions would potentially be triggered by the contact of the blades of the endodontic instruments with the pulp nerve tissue [16]; In addition, in patients with spongiform encephalopathy prions can be found at the trigeminal level, as demonstrated by Guiroy et al. [17, 18].

The WHO guidelines report the following methods as methods for the inactivation of the prion and its denaturation, as reported by Walker et al. [13]:

$\checkmark$ Immersion in sodium hypochlorite $(20,000 \mathrm{ppm}$ of available chlorine) for one hour;

$\checkmark$ Boiling in 1M sodium hydroxide for one hour;

$\checkmark$ Autoclaving under vacuum at $121^{\circ} \mathrm{C}$ for 30-90 minutes in the presence of $2 \mathrm{M}$ sodium hydroxide [19].
These methods alter the surface of the instruments and are not applicable to dental endodontic instruments as reported by Sonntag et al. [20].

The fracture of endodontic instruments inside the canal is a problem that is not always easy to solve [2123]. The potential reuse of many endodontic instruments after sterilization procedures raises the question of how much these processes influence their physical and mechanical properties. There are three possible answers to this question: the instrument properties deteriorate, improve or are unaffected [24].

Some studies suggest that sterilization procedures have no influence on these instruments, but the results in the literature do not always agree. For example, D. Zhao et al. [25] reported an increase in the cyclic fatigue resistance of HyFlex CM, Twisted File and K3XF instruments (autoclave sterilization was performed at $134{ }^{\circ} \mathrm{C}$ with a pressure of 30 psi for $5 \mathrm{~min}$ ), and Viana et al. [26] reported that the average number of cycles (916-950 cycles to failure) before failure was higher for instruments that were heat sterilized. In contrast, a recent study on $\mathrm{NiTi}$ instruments conducted by Masoud Khabiri et al. [27] indicated that sterilization had no influence on cyclic fatigue, while Silvaggio and Hicks [28] demonstrated that 10 autoclave cycles did not increase the risk of fracture of the files. Resistance to cyclic fatigue is not the only physical and mechanical property affected by sterilization procedures; other effects include resistance to torsional fatigue, on which recent studies disagree: Casper et al. [29] reported the improvement of M-Wire alloys on torsional fatigue strength, whereas King et al. [30] reported the deterioration of Gt Series X instruments. Furthermore, sterilization procedures can negatively affect the cutting efficiency and have corrosive effects on the surface of instruments, as demonstrated in a 1999 study by Rapisarda et al. [31], who reported a reduction cutting efficiency for ProFile instruments of $20 \%-50 \%$ after $7-14$ cycles autoclave.

Thus, the literature reports conflicting findings about changes in endodontic instruments after sterilization procedures. These disagreements may be due to the multitude of instruments and methods used in endodontics and the different methods of sterilization and disinfection [32].

The heterogeneity of the results of the various studies could also depend on the high heterogeneity of the measurement apparatuses, in particular for the measurement of cyclic fatigue, Plotino [33] reports in a 2009 literature review as an ideal hypothetical model the curved canals of natural teeth, but the problem as set out by the author of the review and in the standardization of measurement.

All instruments for the measurement of cyclic fatigue that reproduce the artificial canal through a curved cylindrical tube are subject to wear and the endodontic instruments used within them have a degree of freedom following an unpredictable trajectory and without a precise measurement of radius and angle of curvature. In the realization of the measuring apparatus for cyclic fatigue, both 
the angle and the radius of curvature of the artificial canal are fundamental, which differ in the various studies on the resistance to cyclic fatigue [33].

NiTi endodontic instruments consist of a crystalline lattice with a body-centered cubic shape which takes the name of austenite which, following thermal variations or the application of forces, becomes a monoclinic structure called martensite [34].

For NiTi alloys the martensitic transformations are of the displastic type, obtained by cooling the austenitic phase with the release of heat [35]. The transformation from austenite to martensite consists of 2 moments: in the first we have all the atomic movements necessary to produce the new structure and in the second the adaptation of shape and volume with a change in the crystal lattice that can take place with the slip, which is permanent, or the twinning which is reversible (and is preferable if you want to get a return of shape) [36].

Following a lowering of the temperature which varies according to the type of alloy, the crystal lattice acquires an easily deformable martensitic type configuration, with a low yield point; while upon heating, the alloy forms an austenitic lattice [37]; Under the application of a force, the austenitic alloy behaves in a similar way, passing to a martensitic crystalline form through an intermediate transformation phase that can accommodate greater stress without increasing the tension. Therefore, an endodontic instrument while working inside the endodontic canals is subjected to deformation forces in which there is the transition from the austenitic to martensitic phase through a transformation phase. In the transformation phase, the instrument will show superplasticity characteristics before reaching the martensitic phase which could be followed by yielding and rupture [38, 39].

Previous studies on the subject by the same research group have focused on the torsional property and surface alterations of endodontic instruments subjected to sterilization, focusing neither on cyclic fatigue nor deformation [7, 40, 41]. To date, no other systematic reviews have addressed these topics (cyclic fatigue, deformation, torsional fatigue, corrosion or surface alterations, cutting efficiency) in relation to sterilization.

The purpose of this review is to provide the widest and most up-to-date overview of the topic through a systematic methodology involving the screening and selection of articles [42, 43]. Our hypothesis is that not all alterations induced by the autoclave have a negative effect on rotating endodontic instruments.

\section{Materials and methods}

The following systematic review was performed in accordance with the PRISMA protocol (Preferred Reporting Items for Systematic reviews and Meta-Analyses): the outcomes, the data extraction process and the methods for their quantitative and qualitative synthesis were previously agreed upon by 3 reviewers.

The protocol and methodology adopted for this review have been used for previous systematic reviews by the same research group.

Articles that were eligible for inclusion in this review were in vitro or clinical studies that evaluated the influence of disinfection and sterilization procedures on rotary endodontic instruments and endodontic files. Reports that were not written in English, were published before 1980 or were published in journals of national interest only were excluded. We selected only articles published in the last 4 decades because the instruments and sterilization methods have profoundly changed. Four research outcomes were defined:

- Primary outcome: influence of sterilization on the resistance to cyclic fatigue;

- Secondary outcome: influence of sterilization on the resistance to torsional fatigue;

- Tertiary outcome: alterations induced by sterilization procedures on the surface of endodontic instruments;

- Quaternary outcome: Reduction in cutting efficiency induced by sterilization procedures.

The studies were identified through bibliographic searches in electronic databases and the manual review of the biobibliography of previous systematic reviews conducted on the subject.

The literature search was conducted in the "PubMed" and "Scopus" search engines. The original search was conducted between 12.12.2020 and 01.03.2021, and a final search was conducted on 10.04.2021 for a partial update of the records.

We searched for different terms using the following combinations: "Endodontic sterilization" "endodontic autoclave" "cyclic fatigue" AND "sterilization"; "torsional” AND "sterilization"; "cutting efficiency” AND "sterilization" "surface characteristics" AND "sterilization”; “Corrosion” AND "sterilization”. Bibliographic citations of previous systematic reviews on the subject were also analyzed. Table 1 describes the research methodology for keyword searches in databases and article selection.

The "records" obtained from the search were subsequently screened by two independent reviewers (M.D. and D.S.). Situations of uncertainty or disagreement between the 2 reviewers were resolved by a third supervisor. Agreement between the 2 screening reviewers was measured by the $\mathrm{K}$ statistic, and $\mathrm{K}=0.68$.

After applying the preliminary eligibility criteria (articles in English and published after 1979) through the application of filters in search engines, duplicates were removed with the aid of the EndNote X8 software (Thomson Reuters , Clarivate Analytics, Philadelphia, PA, USA). Then, the two reviewers independently removed articles and studies that were not related to the topics of the re- 
Table 1. Inclusion and exclusion criteria.

\begin{tabular}{|c|c|c|}
\hline Category & Exclusion criteria & Inclusion criteria \\
\hline Publication language & Not English & English \\
\hline Study type & Reviews, systematic reviews , case reports, case series, & in vitro studies \\
\hline \multirow[t]{3}{*}{ Data characteristics } & $\begin{array}{l}\text { I. Articles that do not report data on physical and mechanical characteristics } \\
\text { (resistance to cyclic and torsional fatigue, alterations of the surface of the } \\
\text { instruments, cutting efficiency) following sterilization procedures; }\end{array}$ & $\begin{array}{l}\text { A. To include all studies reporting data on } \\
\text { cyclic and torsional fatigue after sterilization; }\end{array}$ \\
\hline & $\begin{array}{l}\text { II. To exclude all studies that measured the variation in resistance to torsional } \\
\text { and cyclic fatigue as well as surface alterations and cutting efficiency after } \\
\text { shaping procedures of artificial or natural canals. }\end{array}$ & $\begin{array}{l}\text { B. To include all studies that report data on } \\
\text { the variation of the topographical surface af- } \\
\text { ter sterilization; }\end{array}$ \\
\hline & & $\begin{array}{l}\text { C. To include all studies reporting data on cut- } \\
\text { ting efficiency after sterilization. }\end{array}$ \\
\hline Year of publication & Published before 1979 & Published after 1979 \\
\hline \multicolumn{3}{|c|}{ further inclusion and exclusion criteria applied to the network meta-analysis } \\
\hline \multirow[t]{2}{*}{ Data characteristics } & $\begin{array}{l}\text { I. To exclude those data and studies in which the sterilization procedure was } \\
\text { performed not in an autoclave; } \\
\text { II. To exclude those studies that report data without a control (instruments } \\
\text { not subjected to autoclaving cycles or other sterilization procedures); }\end{array}$ & $\begin{array}{l}\text { A. The cyclic fatigue measurement must have } \\
\text { been performed with a curvature angle of } 60 \\
\text { degrees and a radius of curvature of } 5 \mathrm{~mm} \text {; }\end{array}$ \\
\hline & $\begin{array}{l}\text { III. To exclude all data on cyclic fatigue obtained on artificial canals with } \\
\text { a curvature angle and a radius of curvature different from } 60 \text { degrees and } 5 \\
\text { mm. }\end{array}$ & $\begin{array}{l}\text { B. The sterilization procedure must have been } \\
\text { carried out by means of an autoclave ( } 10 \text { cy- } \\
\text { cles). }\end{array}$ \\
\hline
\end{tabular}

view (endodontics and sterilization) by analyzing the title and abstract. The inclusion and exclusion criteria applied to the studies are shown in the Table 1.

Subsequently, studies were included in the qualitative analysis based on the 4 outcomes decided in advance.

The extraction of data from the included studies involved the development of tables and was performed by the two reviewers.

The characteristics of the data were the following: first author, date of publication, bibliographic reference, type of endodontic instrument, method of sterilization and alterations in the instruments induced by sterilization.

\section{Results}

A total of 1195 records were identified in the PubMed and Scopus databases. After screening the articles through the use of filters (restriction by year and language), 996 articles were obtained, and 578 were retained after the removal of duplicates. After the application of the eligibility criteria (all articles relating to the topic of sterilization in endodontics), we arrived at 161 articles, and 103 articles remained after the elimination of duplicates. After the application of exclusion and inclusion criteria, we obtained 51 articles, which were divided according to the topics of interest: outcome 1 (16 studies that investigate the influence of disinfection and sterilization procedures on resistance to cyclic fatigue); outcome 2 (7 articles investigating the influence of disinfection and sterilization procedures on resistance to torsional fatigue); outcome 3 (23 articles investigating the effects of sterilization and disinfection on the surface characteristics of endodontic instruments); outcome 4 (7 articles investigating changes in the cutting efficiency of instruments after sterilization and disinfection procedures). Some articles were included in multiple outcomes.

The studies included in the quantitative analysis were as follows. First outcome: Khabiri et al. 2017 [27], Arias et al. 2014 [44], Zhao et al. 2016 [25], Plotino, et al. 2012 [45], Mize et al. 1998 [46], Viana et al. 2006 [26], Sharroufna and Mashyakhy, 2020 [47], Das et al. 2019 [48], Alshwaimi 2019 [49], Arias et al. 2020 [50], Kim et al. 2020 [51], Li et al. 2015 [52], Yang et al. 2018 [53], Pedullà et al. 2011 [54], Bulem et al. 2013 [55], Özyürek et al. 2017 [56],Second outcome: Iverson et al. 1985 [57], Chenail et al. 1986 [58], Hilt et al. 2000 [59], Silvaggio et al. 1997 [28], Canalda-Sahli et al. 1998 [60], King et al. 2011 [30], Casper et al. 2011 [29]. Third outcome: Razavian et al. 2016 [61], Alexandrou et al. 2005 [62], Qaed et al. 2018 [63], Li et al. 2015 [52], Alexandrou et al. 2006 [64], Yang et al. 2018 [53], Yilmaz et al. 2017 [65], Nair et al. 2015 [66], Valois et al. 2008 [67], Spagnuolo et al. 2012 [68], Inan et al. 2007 [69], Can Saglam et al. 2015 [70], Das et al. 2019 [48], Cai et al. 2017 [71], Prasad et al. 2014 [72], Saglam et al. 2012 [73], Topuz et al. 2008 [74], Ametrano et al. 2011 [75], Fayyad and Mahran [76], Uslu et al. 2018 [77], Shahi et al. 2012 [78], Stokes et al. 1999 [79], Casella et al. 2011 [80]. Fourth outcome: Schafer et al. 2002 [81], Haikel et al. 1996 [82], Rapisarda et al. 1999 [31], Seago et al. 2015 [83], Haikel et al. 1998 [84], Morrison et al. 1989 [85], Neal et al. 1983 [86]. There are 4 articles included in the network meta-analysis for the first outcome: Sharroufna and Mashyakhy, 2020 [47], Kim et al. 2020 [51], Özyürek et al. 2017 [56], Plotino, et al. 2012 [45]. 


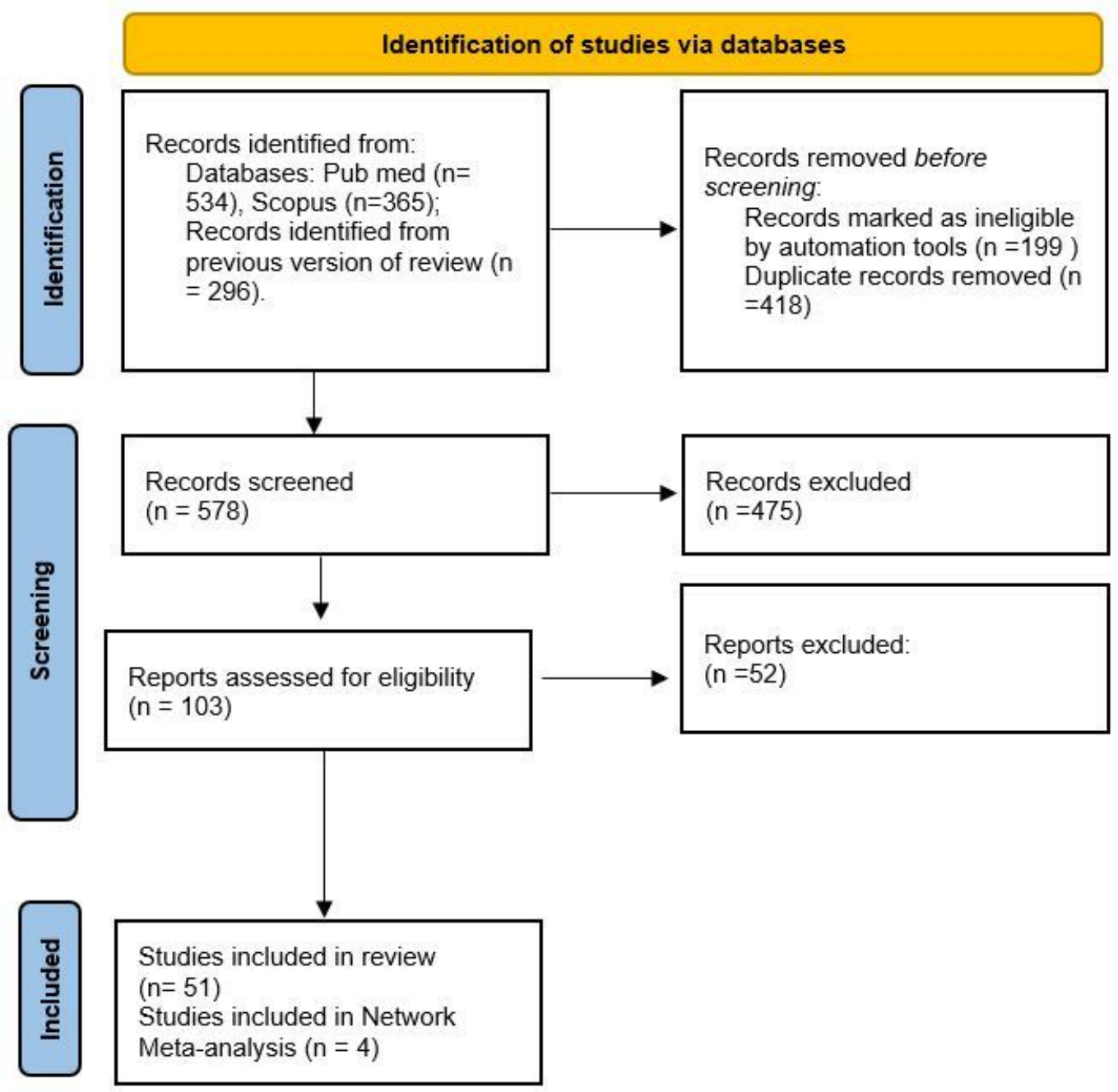

Fig. 1. Flowchart of the different phases of the systematic review.

The entire selection and screening procedure, as described in Table 2 (Ref. [7, 40, 41, 87-90]), is presented in the flowchart in Fig. 1.

\section{Discussion}

\subsection{Cyclic fatigue}

Cyclic fatigue is one of the main causes of fractures of rotating instruments made of NiTi. With the advent of new NiTi alloys and the introduction of new production methods, the occurrence of cyclic fatigue has been increasingly reduced [36, 91-93]. NiTi alloys today have equal atomic concentrations, which renders the austenitic phase very stable. A change in the proportion between titanium and nickel makes the alloy more unstable, and transformation into the super-elastic martensitic phase is favored under stress. After the super-elastic martensitic phase, the instrument undergoes compression and bending cycles, as is usually the case for instruments rotating in curved canals, after which it deforms and breaks [92, 94, 95]. The studies in the literature can be divided into two subgroups: those that investigated the effects of hypochlorite on cyclic fatigue (Table 3, Ref. [54, 55]) and those that investigated the effects of hot sterilization procedures on cyclic fatigue resistance (Table 4, Ref. [25-27, 44-53]).

The studies conducted by Pedullà et al. [54] and Bulem et al. [55] agree that 5 percent sodium hypochlorite has no influence on cyclic fatigue, neither worsening nor improving it, regardless of whether the chemical is used as a canal irrigant or as a disinfectant agent for the instruments.

Other studies that support a lack of influence on cyclic fatigue are those conducted by Mize et al. [46], Khabiri et al. [27] and Kim et al. [51]. In these studies, there was no statistically significant increase or decrease. The investigated instruments were a Profile rotary file, ProTaper Universal, K3XF, HyFlex EDM and TF adaptive.

Conversely, other studies describe an increase in resistance to cyclic fatigue for the K3, K3XF, Mtwo, ProTaper, GT, GTX, Vortex, EdgeFile X7 and Twisted file instruments [26, 45, 47, 52]. 
Table 2. Complete overview of the search methodology Total articles after screening $=1095$, after removed overlaps $=578$ article included $=51$.

\begin{tabular}{|c|c|c|c|c|c|c|}
\hline Database - Provider & Key words and search details & $\begin{array}{l}\text { Number of } \\
\text { records }\end{array}$ & $\begin{array}{l}\text { Number of records) after } \\
\text { restriction by year of publication } \\
\text { and language (last } 40 \text { years) }\end{array}$ & $\begin{array}{c}\text { After remove } \\
\text { overlaps articles }\end{array}$ & $\begin{array}{l}\text { Number of remaining } \\
\text { articles after screening for } \\
\text { the latest review topic }\end{array}$ & $\begin{array}{l}\text { Article remaining after } \\
\text { application of the inclusion } \\
\text { and exclusion criteria }\end{array}$ \\
\hline Pub-med & $\begin{array}{l}\text { Search: “endodontic” AND "sterilization” Sort by: Most } \\
\text { Recent } \\
\text { "endodontic" [All Fields] AND “sterilization” [All Fields] }\end{array}$ & 224 & 161 & & & \\
\hline Pub-med & $\begin{array}{l}\text { Search: “endodontic” AND “autoclave” Sort by: Most Re- } \\
\text { cent } \\
\text { "endodontic” [All Fields] AND “autoclave” [All Fields] }\end{array}$ & 45 & 42 & & & \\
\hline Pub-med & $\begin{array}{l}\text { Search: "cyclic fatigue” AND "sterilization" Sort by: } \\
\text { Most Recent } \\
\text { "cyclic fatigue" [All Fields] AND "sterilization" [All } \\
\text { Fields] }\end{array}$ & 29 & 27 & & & \\
\hline Pub-Med & $\begin{array}{l}\text { Search: "torsional” AND “sterilization” Sort by: Most Re- } \\
\text { cent } \\
\text { "torsional” [All Fields] AND “sterilization” [All Fields] }\end{array}$ & 34 & 31 & & & \\
\hline Pub-med & $\begin{array}{l}\text { Search: “cutting efficiency" AND “sterilization” Sort by: } \\
\text { Most Recent } \\
\text { "cutting efficiency” [All Fields] AND “sterilization" [All } \\
\text { Fields] }\end{array}$ & 17 & 17 & & & \\
\hline Pub-med & $\begin{array}{l}\text { Search: "surface characteristics" AND "sterilization" Sort } \\
\text { by: Most Recent } \\
\text { "surface characteristics" [All Fields] AND "sterilization" } \\
\text { [All Fields] }\end{array}$ & 34 & 33 & & & \\
\hline Pub-med & $\begin{array}{l}\text { Search: “Corrosion” AND "sterilization” Sort by: Most } \\
\text { Recent } \\
\text { "Corrosion” [All Fields] AND “sterilization” [All Fields] }\end{array}$ & 151 & 107 & & & \\
\hline Scopus & TITLE-ABS-KEY (endodontic AND sterilization & 301 & 229 & & & \\
\hline Scopus & TITLE-ABS-KEY (“endodontic” AND “autoclave”) & 64 & 60 & & & \\
\hline Dioguardi et al. 2021 [88] & Systematic review & 65 & 62 & & & \\
\hline Silva et al. 2020 [87] & Systematic review & 40 & 40 & & & \\
\hline Dioguardi et al. 2020 [7] & Systematic review & 97 & 95 & & & \\
\hline Jena et al., 2020 [89] & Review & 25 & 24 & & & \\
\hline Dioguardi et al. 2019 [40] & Systematic review & 28 & 28 & & & \\
\hline Rajpurohit and Chowdary, 2019 [90] & Review & 16 & 16 & & & \\
\hline Dioguardi et al. 2019 [41] & Systematic review & 25 & 24 & & & \\
\hline Total records & & 1195 & 996 & 578 & 103 & 51 \\
\hline
\end{tabular}


In contrast to these data, Alshwaimi [49] report a reduction in resistance to cyclic fatigue for Proflexendo rotary files. A decrease was also found for HyFlex EDM in a study by Arias et al. [50].

There is an apparent contrast among the results of different studies. Thus, for a definitive analysis, a metaanalysis should be carried out by extracting data from reports, such as the average number of cycles to failure and the length of fragments. However, there is excessive diversity in the studies, such as different apparatuses to measure cyclic fatigue, different angles of curvature of the artificial canals with which the cyclic fatigue was measured, the heterogeneity of instruments and different numbers of sterilization cycles. These differences can lead to results with a high heterogeneity index, as also indicated by a recent systematic review conducted by Silva et al. [87].

\subsubsection{Network meta-analysis}

In light of the high heterogeneity of the instruments investigated and of the investigation methods that are not always standardized (variations in the radius and angle of curvature), the 2 reviewers decided not to perform a meta-analysis of the data (variation in the number of cycles upon failure after sterilization) comparing instruments never autoclaved and instruments with 10 autoclave cycles, but to perform a Network meta-analysis comparing the different endodontic instruments through an indirect and direct comparison of the various rotating instruments. The data included in the network meta-analysis (mean difference, of the variation of the Number of Cycles to Failure) respects the principle of similarity (only the studies that reported data on NFC on non-sterilized instruments and after 10 sterilizations, obtained with artificial canals with a radius of curvature of $5 \mathrm{~mm}$ and a curvature angle of 60 degrees) since the methodology adopted is similar in each study and therefore comparable (Table 5, Ref. [45, 47, 51, 56]). The network diagram shown in Fig. 2 shows us how the main data of the direct comparisons are mainly on the K3XF, Vortex and PTU nodes with a similar robustness of the lines towards the various nodes.

The general consistency test reports at $\mathrm{Chi}^{2}(1)=$ 30.17, $p=0.0001$.

For the analysis of the effect size, we proceeded through the representation by forest plot Fig. 3.

We then evaluated the instruments that after $10 \mathrm{au}-$ toclave cycles exhibit the lowest reduction in the number of turns at failure as shown in Fig. 4 and Table 6, the probability that the EDM endodontic instrument is the best (with the least reduction of NFCs) is approximately $71.8 \%$ and the probability that it is at least the second best is $6.4 \%$. In the SUCRA (surface under the cumulative ranking), in fact, the surface for the EDM instrument reaches almost 90\%, while we have that the PTG endodontic instrument has the probability that it is the best is $20.4 \%$ and $51.2 \%$ that it is the second, with a SUCRA also of $90 \%$.

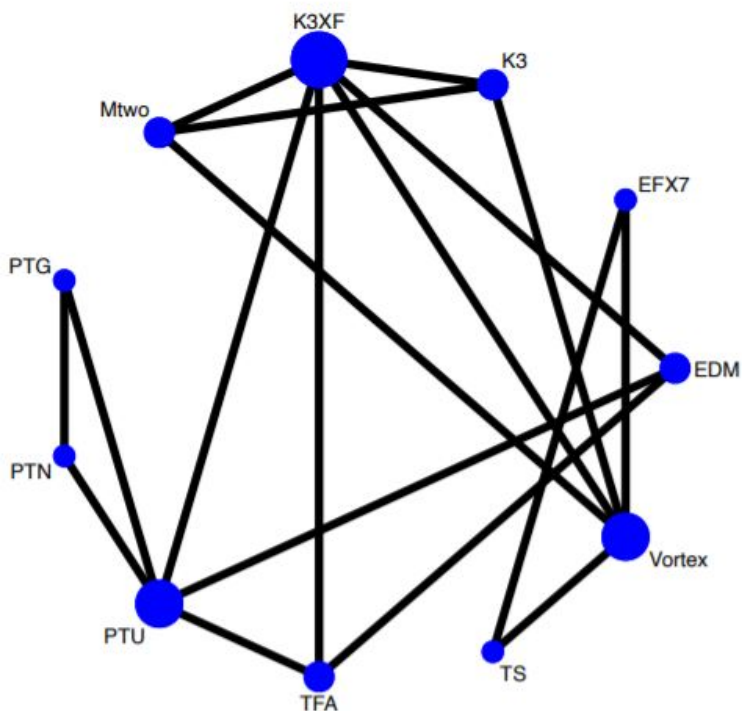

Fig. 2. Network geometry. The size of the 11 nodes, one for each treatment, indicates the number of studies included in the corresponding nodes, while the thickness of the lines connecting 2 nodes indicates the amount of relevant data (PTG, Protaper Gold; PTN, Protaper Next; PTU, Protaper Universal; TFA, TF adaptive file; TS, TRUShape; Vortex; EDM, HyFlex EDM; EFX7, EdgeFile X7; K3, K3XF, Mtwo).

\subsection{Deformations and torsional fatigue}

Among the fundamental properties that an endodontic instrument must have in order to be safely used in the endodontic canal is torsion resistance.

Torsion is defined as the stress to which an elongated body is subjected when one of its sections is rotated with respect to another or the effect of such stress [96].

In the most up-to-date methods, instruments such as K-files, NiTi files, Unifile and flex-or-files (generally $2 \%$ tapered instruments) are used to explore the endodontic canal and execute the glide path [97]; These instruments must exhibit characteristics of flexibility and resistance to torsion and lt the end of each clinical use, it is important to inspect and eliminate instruments that have deformations or show stretching of the blades [98].

Iverson et al. [57] investigated the K-Flex and Burns Unifile instruments and reported that the torsion resistance of K-Flex files increased by $12.7 \%$ and $9.7 \%$ after heat and cold sterilization, respectively, compared with that of the controls and files subjected to other sterilization methods. These data are in contrast to the results reported by Chenail et al. [58], who studied the same instruments but observed no statistically significant influence, and agree with the findings of Hilt et al. [59], who reported no negative or positive influence on NiTi K-files.

These studies show that, for manual endodontic instruments with a constant taper of $2 \%$ made of both steel and nickel titanium (K-file, NiTi file), sterilization has neither a positive nor negative influence. 


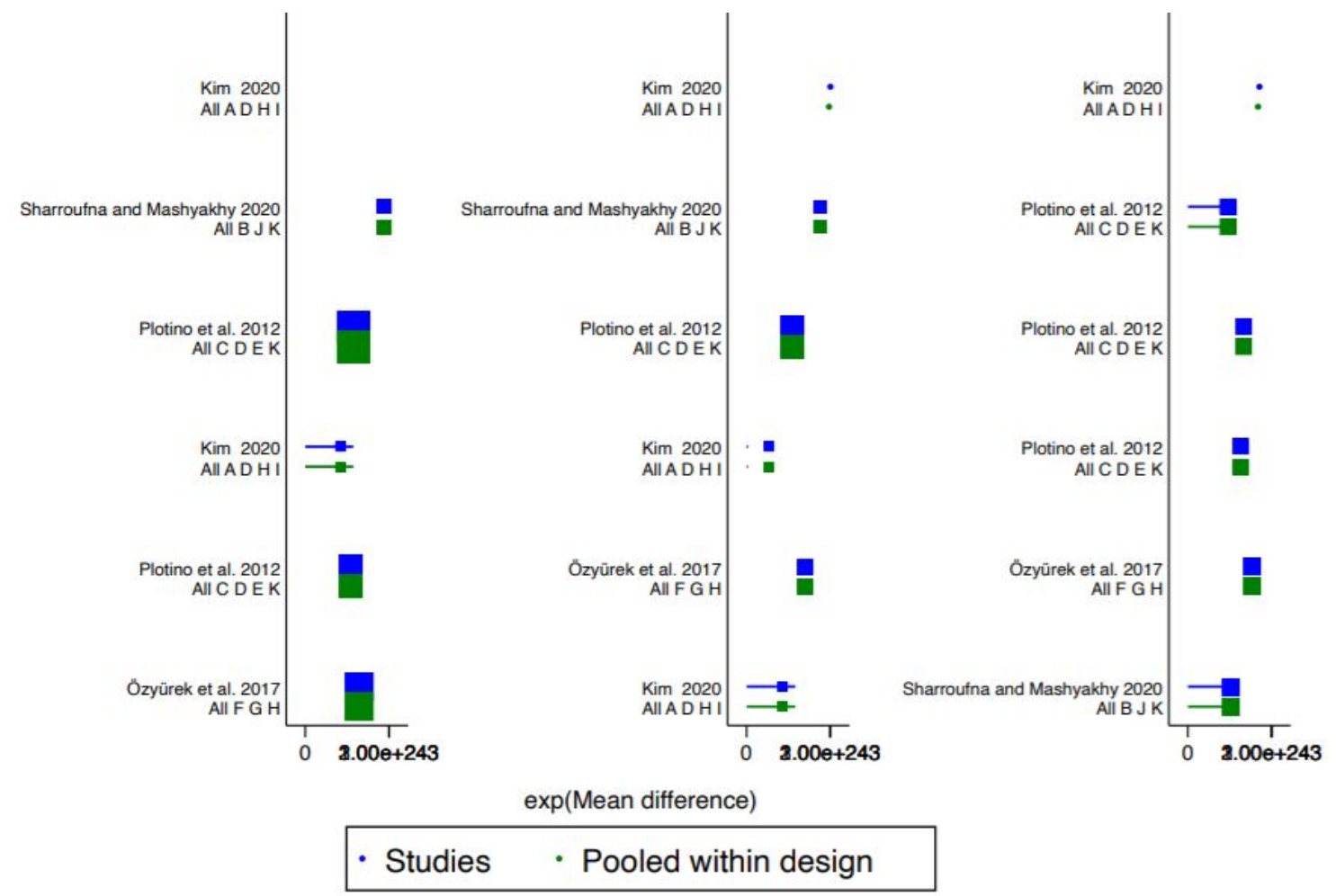

Test of consistency: chi2(1) $=30.17, \mathrm{P}=0.000$

Fig. 3. Network Forest plot. All direct and mixed comparisons. A: EDM, B: EFX7, C: K3, D: K3XF, E: Mtwo, F: PTG, G: PTN, H: PTU, I: TFA, J: TS, K: Vortex.
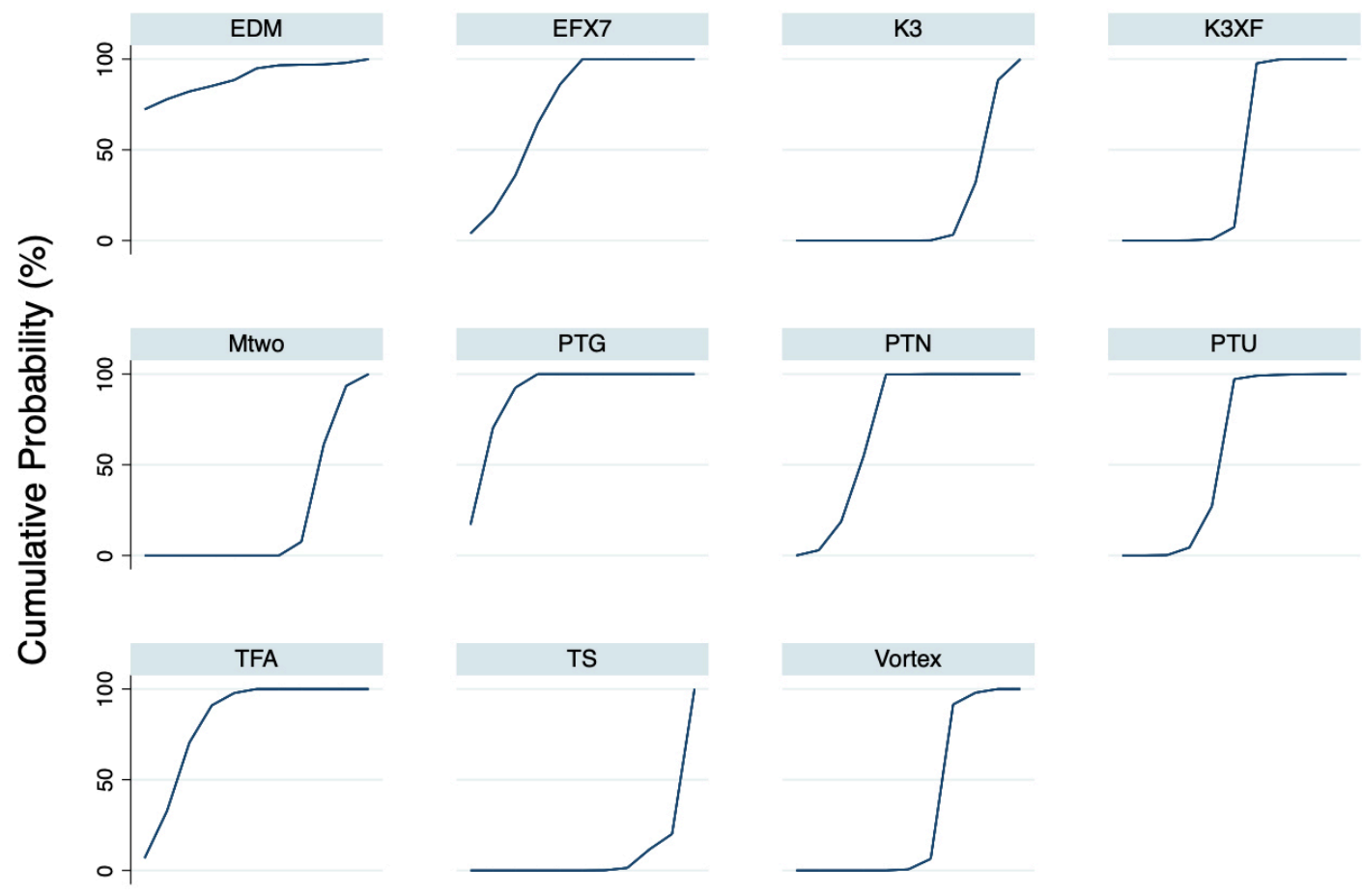

Rank

Fig. 4. Results of the network rank test. Graphical ranking; SUCRA: surface under the cumulative ranking. The higher the SUCRA value, the greater the probability that one instrument is better than the others with a lower reduction of NCFs after 10 cycles of sterilization. 
Table 3. Studies that investigated the effects of hypochlorite on cyclic fatigue.

\begin{tabular}{|c|c|c|c|}
\hline Autor, data & Instruments & Sterilization methods & $\begin{array}{l}\text { Influence on resistance to } \\
\text { cyclic fatigue }\end{array}$ \\
\hline Pedullà et al. 2011 [54] & Twisted Files, Revo S, Mtwo files & $5 \% \mathrm{NaOCl}$ solution & No influence \\
\hline Bulem et al. 2013 [55] & $\begin{array}{l}\text { ProFile, FlexMaster, Mtwo and } \\
\text { TwistedFiles }\end{array}$ & $\begin{array}{l}\text { immersed in } \mathrm{NaOCl} \text {; immersed in } \mathrm{NaOCl} \text { and ster- } \\
\text { ilized in one autoclave cycle; } 5 \text { cycles immersed in } \\
\mathrm{NaOCl} \text { and sterilized in autoclave and not immersed } \\
\text { in } \mathrm{NaOCl} \text { and not sterilized }\end{array}$ & No influence \\
\hline
\end{tabular}

Table 4. Studies that investigate the effects of sterilization procedures on cyclic fatigue.

\begin{tabular}{|c|c|c|c|}
\hline Autor, data & Instruments & Sterilization methods & $\begin{array}{l}\text { Influence on resistance to cyclic fatigue } \\
\text { in relation to sterilization cycles }\end{array}$ \\
\hline Khabiri et al. 2017 [27] & $\begin{array}{l}90 \text { Nickel-Titanium } 642 \text { rotary } \\
\text { files \#30 with } 0.06 \text { tape }\end{array}$ & $\begin{array}{l}134{ }^{\circ} \mathrm{C} \text {, } 30 \text { psi for } 36 \text { minutes (au- } \\
\text { toclave) }\end{array}$ & No influence \\
\hline Arias et al. 2014 [44] & GT, GTX files & immersed in $\mathrm{NaOCl}$ and Autoclave & Increase resistance \\
\hline Zhao et al. 2016 [25] & HyFlex CM, TF and K3XF & $\begin{array}{l}\text { autoclave sterilization was per- } \\
\text { formed at } 134{ }^{\circ} \mathrm{C} \text {, with a pressure } \\
\text { of } 30 \mathrm{psi} \text {, for } 5 \mathrm{~min}\end{array}$ & Increase resistance \\
\hline Plotino, et al. 2012 [45] & K3, Mtwo, Vortex, and K3 XF & autoclave & Increase resistance (only k3 XF) \\
\hline Mize et al. 1998 [46] & $\mathrm{Ni}$-Ti instruments & $\begin{array}{l}135^{\circ} \mathrm{C} \text { and } 30 \text { to } 35 \text { psi for } 5 \text { min- } \\
\text { utes }\end{array}$ & No influence \\
\hline Viana et al. 2006 [26] & ProFile & $\begin{array}{l}\text { Dry heat sterilization cycles } 170 \\
{ }^{\circ} \mathrm{C}, 40 \text { minutes }\end{array}$ & Increase resistance \\
\hline Sharroufna and Mashyakhy, 2020 [47] & $\begin{array}{l}\text { EdgeFile X7, Vortex Blue, } \\
\text { TRUShape }\end{array}$ & $\begin{array}{l}\text { autoclave sterilization ( } 10 \text { cycles }) \text { at } \\
\text { a temperature of } 134{ }^{\circ} \mathrm{C} \text { for } 35 \text { min- } \\
\text { utes }\end{array}$ & Increase resistance (only EdgeFile X7) \\
\hline Das et al. 2019 [48] & Hyflex CM, Hyflex EDM & $\begin{array}{l}\text { autoclave sterilization at } 121^{\circ} \mathrm{C} \text { at } \\
15 \text { psi for } 15 \mathrm{~min}\end{array}$ & Not applicable \\
\hline Alshwaimi 2019 [49] & Proflexendo rotary files & $134^{\circ} \mathrm{C}$ for $25 \mathrm{~min}$ & $\begin{array}{l}\text { Reduced the cyclic fatigue resistance of } \\
\text { Proflexendo files }\end{array}$ \\
\hline Arias et al. 2020 [50] & Hyflex EDM, TRUShape & $\begin{array}{l}136{ }^{\circ} \mathrm{C}, 4 \text { minutes; Gamma irradia- } \\
\text { tion }\end{array}$ & $\begin{array}{l}\text { Gamma-irradiation decreased cyclic fa- } \\
\text { tigue resistance of TRUShape; steriliza- } \\
\text { tion decreased fatigue resistance Hyflex } \\
\text { EDM }\end{array}$ \\
\hline Kim et al. 2020 [51] & $\begin{array}{l}\text { ProTaper Universal, K3XF, } \\
\text { HyFlex EDM, and TF adaptive }\end{array}$ & $\begin{array}{l}\text { autoclave ( } 10 \text { cycles) } 132{ }^{\circ} \mathrm{C} \text { for } 15 \\
\text { min }\end{array}$ & No influence \\
\hline Li et al. 2015 [52] & K3, Mtwo, ProTaper & $\begin{array}{l}134{ }^{\circ} \mathrm{C} \text {, } 30 \text { psi for } 36 \text { minutes (au- } \\
\text { toclave) }\end{array}$ & Increase resistance \\
\hline Yang et al. 2018 [53] & K3XF, K3 & autoclave & No influence \\
\hline
\end{tabular}

For rotary instruments, the torsional resistance of Profile instruments after sterilization was investigated for the first time by Silvaggio et al. [28] in 1997, who observed an improvement in resistance, and further studies on Twisted files and M-wire alloys also showed improvements [29, 36].

Alazemi et al. [99] reported that HyFlex instruments recovered their shape following clinical use and subsequent autoclaving.

Deterioration was only reported in one study, which was conducted by King et al. [30] on GT Series X files (Table 7, Ref. [28-30, 51, 57-60, 99-101]).

A recent systematic review of the literature conducted by this research group identified a meta-analysis of data on the variations in the deflection angle (the angle that is generated at the moment of fracture) and in the torsional moment of NiTi and steel instruments after sterilization procedures. The data reveal reductions in the torsional fatigue resistance (reduction of the torsional moment) and the deflection angle, but with low statistical significance. The authors of the review cite the high heterogeneity among the included studies as a limitation [40].

\subsection{Corrosion, topographic and surface alterations}

An undesired effect of heat sterilization (autoclave and dry heat sterilization) on the surface of instruments is the formation of surface irregularities or micro-pitting [102]. Corrosion can also occur following the use of sodium hypochlorite or other dental disinfectants [103].

In the reviewed literature, three types of methods were used to analyze the level of corrosion: atomic force microscopy (AFM) [66], scanning electron mi- 
Table 5. Data extracted from the $\mathbf{4}$ articles included in the network meta-analysis are reported.

\begin{tabular}{|c|c|c|c|c|c|c|c|}
\hline & Intruments & Cycles autoclave & Number & N.C.F. & S.D. & Mean difference & S.D.M.D. \\
\hline \multirow[t]{6}{*}{ Sharroufna and Mashyakhy, 2020 [47] } & EFX7 & 0 & 12 & 755.8 & \pm 175.4 & -443.0 & 219.2 \\
\hline & & 10 & 12 & 1198.8 & \pm 255.6 & & \\
\hline & Vortex & 0 & 12 & 568.7 & \pm 174.6 & -37.4 & 160.53 \\
\hline & & 10 & 12 & 606.1 & \pm 145.1 & & \\
\hline & TS & 0 & 12 & 442.2 & \pm 80.9 & 45.6 & 80.8 \\
\hline & & 10 & 12 & 487.8 & \pm 80.7 & & \\
\hline \multirow[t]{8}{*}{ Kim 2020 [51] } & PTU & 0 & 10 & 1712.9 & \pm 321.6 & 270.1 & 330.26 \\
\hline & & 10 & 10 & 1442.8 & \pm 338.7 & & \\
\hline & EDM & 0 & 10 & 11645.3 & \pm 1768.0 & -290.6 & 1702.75 \\
\hline & & 10 & 10 & 11935.9 & \pm 1634.9 & & \\
\hline & TFA & 0 & 10 & 1344.7 & \pm 297.00 & 78.7 & 330.71 \\
\hline & & 10 & 10 & 1266.0 & \pm 361.3 & & \\
\hline & K3XF & 0 & 10 & 1726.8 & \pm 383.1 & 473.9 & 329.99 \\
\hline & & 10 & 10 & 1252.9 & \pm 266.5 & & \\
\hline \multirow[t]{8}{*}{ Plotino et al. 2012 [45] } & K3 & 0 & 12 & 439 & \pm 64 & 15 & 54.52 \\
\hline & & 10 & 12 & 424 & \pm 43 & & \\
\hline & Mtwo & 0 & 12 & 419 & \pm 45 & 10 & 48.09 \\
\hline & & 10 & 12 & 409 & \pm 51 & & \\
\hline & Vortex & 0 & 12 & 454 & \pm 95 & -26 & 99.60 \\
\hline & & 10 & 12 & 480 & 104 & & \\
\hline & K3XF & 0 & 12 & 651 & \pm 149 & -111 & 175.79 \\
\hline & & 10 & 12 & 762 & \pm 199 & & \\
\hline \multirow[t]{6}{*}{ Özyürek et al. 2017 [56] } & PTG & 0 & 20 & 1045.21 & \pm 198.24 & -261.13 & 224.62 \\
\hline & & 10 & 20 & 1306.34 & \pm 248.22 & & \\
\hline & PTN & 0 & 20 & 525.44 & \pm 94.67 & -98.82 & 104.09 \\
\hline & & 10 & 20 & 624.26 & \pm 112.72 & & \\
\hline & PTU & 0 & 20 & 248.12 & \pm 32.52 & -3.97 & 33.06 \\
\hline & & 10 & 20 & 252.09 & \pm 33.59 & & \\
\hline
\end{tabular}

Table 6. The columns show the probability expressed as a percentage that each instrument is the best.

\begin{tabular}{lccccccccccc}
\hline Rank & EDM & EFX7 & K3 & K3XF & Mtwo & PTG & PTN & PTU & TFA & TS & Vortex \\
\hline Best & 71.8 & 2.4 & 0.0 & 0.0 & 0.0 & 20.4 & 0.0 & 0.0 & 5.4 & 0.0 & 0.0 \\
2nd & 6.4 & 10.9 & 0.0 & 0.0 & 0.0 & 51.9 & 3.6 & 0.0 & 27.2 & 0.0 & 0.0 \\
3rd & 4.1 & 20.3 & 0.0 & 0.0 & 0.0 & 21.5 & 16.7 & 0.7 & 36.7 & 0.0 & 0.0 \\
4th & 2.7 & 29.5 & 0.0 & 0.0 & 0.0 & 6.2 & 36.8 & 4.7 & 20.1 & 0.0 & 0.0 \\
5th & 1.9 & 21.7 & 0.0 & 0.4 & 0.0 & 0.0 & 42.8 & 24.1 & 9.1 & 0.0 & 0.0 \\
6th & 7.2 & 15.2 & 0.0 & 7.6 & 0.0 & 0.0 & 0.1 & 68.3 & 1.5 & 0.0 & 0.1 \\
7th & 1.8 & 0.0 & 0.0 & 90.0 & 0.1 & 0.0 & 0.0 & 1.9 & 0.0 & 0.2 & 6.0 \\
8th & 0.7 & 0.0 & 4.2 & 2.0 & 5.7 & 0.0 & 0.0 & 0.2 & 0.0 & 1.6 & 85.6 \\
9th & 0.3 & 0.0 & 31.2 & 0.0 & 53.5 & 0.0 & 0.0 & 0.1 & 0.0 & 9.1 & 5.8 \\
10th & 0.4 & 0.0 & 53.2 & 0.0 & 34.0 & 0.0 & 0.0 & 0.0 & 0.0 & 9.9 & 2.5 \\
Worst & 2.7 & 0.0 & 11.4 & 0.0 & 6.7 & 0.0 & 0.0 & 0.0 & 0.0 & 79.2 & 0.0 \\
Mean rank & 2.2 & 4.0 & 9.7 & 6.9 & 9.4 & 2.1 & 4.2 & 5.7 & 3.0 & 10.7 & 8.0 \\
SUCRA & 0.9 & 0.7 & 0.1 & 0.4 & 0.2 & 0.9 & 0.7 & 0.5 & 0.8 & 0.0 & 0.3 \\
\hline
\end{tabular}

croscopy (SEM) [64] and electrochemical methods (saturated calomel electrode (SCE), open circuit potential (OCP) and Electrochemical Impedance Spectroscopy (EIS)) [78].

We divided the articles into three sub-groups and extracted the corresponding data, which are reported in three different tables.

\subsubsection{Scanning electron microscopy}

SEM analysis showed the presence of topographical alterations on the surface. These alterations are already visible after the first autoclave cycle and can repre- sent points where microcracks are induced in the structure, indicating cyclic or torsional fatigue failure.

Corrosion resistance is higher for alloys with equal atomic concentrations of nickel and titanium, and corrosion phenomena are more evident for alloys (46 titanium alloys, 56 nickel) with chromium inclusions, which facilitate corrosion through the formation of intermediate alloys [104].

Qaed et al. [63] observed these superficial alterations on AlphaKite and Revo-S NiTi rotary files, with an increase in surface changes after three cycles at a tempera- 
Table 7. Characteristic of the main studies on the influence of sterilization procedures on resistance to torsional fatigue.

\begin{tabular}{|c|c|c|c|}
\hline Autor, data & Sterilization methods & Instruments & Torsion resistance \\
\hline Iverson et al. 1985 [57] & Hot sterilization & K flex, Burs unifile & $\begin{array}{l}\text { Increase for burns unifile after } \\
10 \text { sterilization cycles }\end{array}$ \\
\hline Chenail et al. 1986 [58] & Cold and dry heat sterilization & K flex, Burs unifile & No influence \\
\hline Hilt et al. 2000 [59] & Hot sterilization & $\mathrm{K}$ file in acciaaio and in $\mathrm{NiTi}$ & No influence \\
\hline Silvaggio et al. 1997 [28] & Hot sterilization & Profile & Increase resistance \\
\hline Canalda-Sahli et al. 1998 [60] & Autoclaving & Nitiflex Naviflex Microtitane Flexofile Flex-R & Increase for $\mathrm{NiTi}$ \\
\hline King et al. 2011 [30] & Autoclaving & Gt serie $\mathrm{x}$ twisted file & $\begin{array}{l}\text { Reduction Gt serie x Increase } \\
\text { twisted file }\end{array}$ \\
\hline Casper et al. 2011 [29] & Autoclaving & Profile Vortex Twisted Files CM Wire file & Increase CM Mwire \\
\hline Alazemi et al. 2014 [99] & Autoclaving & HyFlex CM & $\begin{array}{l}\text { Form recovery after steriliza- } \\
\text { tion }\end{array}$ \\
\hline Kim et al. 2020 [51] & Autoclaving & $\begin{array}{l}\text { ProTaper Universal, K3XF, HyFlex EDM, and } \\
\text { TF adaptive }\end{array}$ & No influence \\
\hline Testarelli et al. 2003 [100] & Autoclaving $124{ }^{\circ} \mathrm{C} 2.2 \mathrm{bar}$, for $20 \mathrm{~min}$ & Hero & No influence \\
\hline Haïkel et al. 2003 [101] & hot sterilization, $180^{\circ} \mathrm{C} 2.2$ bar $2 \mathrm{~h}$ & Unifile, Flexofile and H-File & No influence \\
\hline
\end{tabular}

Table 8. Characteristic of studies performed with SEM analysis. The superficial alterations found on the instruments are highlighted following the various disinfection and sterilization processes.

\begin{tabular}{|c|c|c|c|}
\hline Autor, data & Instruments & Sterilization methods & Results \\
\hline \multirow[t]{4}{*}{ Razavian et al. 2016 [61] } & \multirow[t]{4}{*}{ S-Files } & 1,5 and 10 autoclave & $\mathrm{O}=$ Debris and roughness \\
\hline & & Cycles & $1=$ No significant \\
\hline & & & 5 = Significant increase in roughness \\
\hline & & & $10=$ Significant increase in roughness \\
\hline \multirow[t]{3}{*}{ Alexandrou et al. 2005 [62] } & \multirow[t]{3}{*}{ Mani NRT NiTi } & 1,6 and 11 autoclave & $1=$ No significant \\
\hline & & cycles & $6=$ No significant \\
\hline & & & $11=$ Significant increase in roughness \\
\hline \multirow[t]{9}{*}{ Qaed et al. 2018 [63] } & \multirow[t]{4}{*}{ Revo-S NiTi rotary } & Control & show a smoother surface with few machining grooves \\
\hline & & $\begin{array}{l}\text { each instrument } 3 \text { shaped channels with } \\
\text { a single autoclave cycle }\end{array}$ & dulling and blunting of the cutting edges is predominant \\
\hline & & each instrument 9 shaped channels with & showed plastic deformation, disruption in the surface with \\
\hline & & a 3 autoclave cycle & metal flakes \\
\hline & \multirow[t]{5}{*}{ AlphaKite } & control & $\begin{array}{l}\text { gross machining grooves on their surface with no pits, } \\
\text { strips or disruption }\end{array}$ \\
\hline & & each instrument 3 shaped channels with & disruption of cutting edges \\
\hline & & a single autoclave cycle & \\
\hline & & each instrument 9 shaped channels with & microcracks, metal stripping \\
\hline & & a 3 autoclave cycle & \\
\hline Li et al. 2015 [52] & K2, mtwo, protaper & 10 cycles of sterilization autoclave & $\begin{array}{l}\text { surface and inner imperfections in all instruments were in- } \\
\text { tensified greatly after } 10 \text { cycles of sterilization }\end{array}$ \\
\hline Alexandrou et al. 2006 [64] & ProFile, Flexmaster & 11 autoclave cycles & $\begin{array}{l}\text { Increased roughness was observed in all samples that were } \\
\text { exposed to repeated sterilizations }\end{array}$ \\
\hline Yang et al. 2018 [53] & K3XF, K3 & 10, 20 and 30 Autoclave cycles & $\begin{array}{l}\text { The surface roughness of K3XF was increased after auto- } \\
\text { clave }\end{array}$ \\
\hline
\end{tabular}

ture of under $121^{\circ} \mathrm{C}$ at 15 psi for 30 minutes. These data were confirmed by the SEM studies of Alexandrou et al. in 2005 and 2006 [62, 64] and Razavian et al. in 2016 [61] (Table 8, Ref. [52, 53, 61-64]).

Studies on longitudinal sections were conducted by Alexandrou et al. [62], who noted a statistically significant increase in the surface roughness of NiTi instruments after 11 autoclave cycles. Moreover, SEM on the longitudinal sections of the inclusions and holes indicated a significant increase from 1 to 11 autoclave cycles [62].

\subsubsection{Atomic force microscopy}

The atomic force microscope consists of a cantilever with a sharp tip (tip) mounted on the end, typically 
Table 9. Characteristic of studies performed with AFM analysis.

\begin{tabular}{|c|c|c|c|}
\hline Autor, data & Instruments & Sterilization methods & Results \\
\hline Yılmaz et al. 2017 [65] & HyFlex EDM & 1, 5 and 10 autoclave cycles & Significant increase in roughness \\
\hline Nair et al. 2015 [66] & Mani NRT NiTi, M two file & 1,5 and 10 autoclaves cycles & Significant increase in roughness \\
\hline Valois et al. 2008 [67] & Greater Taper, ProFile & 1, 5 and 10 autoclaves cycles & Significant increase in roughness \\
\hline Spagnuolo et al. 2012 [68] & $\begin{array}{l}\text { ProTaper, TiN -coated Al- } \\
\text { phaKite }\end{array}$ & 1,5 and 10 autoclaves cycles & Significant increase in roughness \\
\hline Inan et al. 2007 [69] & ProTaper & 1 autoclave cycles & Significant increase in roughness \\
\hline Can Saglam et al. 2015 [70] & $\begin{array}{l}\text { ProTaper retreatment, R-endo, } \\
\text { and Mtwo }\end{array}$ & $\begin{array}{l}\text { autoclaved five times and, } 2 \% \\
\mathrm{NaOCl} \text { or Chloroform }\end{array}$ & Surface alteration \\
\hline Das et al. 2019 [48] & Hyflex CM, Hyflex EDM & autoclave sterilization at & Higher surface roughness \\
\hline Cai et al. 2017 [71] & HyFlex, M3 & $5.25 \% \mathrm{NaOCl}, 17 \%$ Edta & $\begin{array}{l}\text { The surface roughness of } 5.25 \% \mathrm{NaOCl} \text { and } 17 \% \\
\text { EDTA immersed } \mathrm{M} 3 \text { files significantly increased } \\
\text { compared to the control groups }\end{array}$ \\
\hline Prasad et al. 2014 [72] & ProTaper and iRaCe & $5.25 \% \mathrm{NaOCl}, 17 \%$ EDTA & $\begin{array}{l}\text { Short-term contact with } 17 \% \text { EDTA and } 5 \% \mathrm{NaOCl} \\
\text { can cause significant surface deterioration }\end{array}$ \\
\hline Saglam et al. 2012 [73] & ProTaper & $\begin{array}{l}2.5 \% \mathrm{NaOCl}, 5 \% \mathrm{NaOCl}, 2 \% \\
\mathrm{CHX} \text {, and MTAD }\end{array}$ & All tested solutions caused surface alterations \\
\hline Topuz et al. 2008 [74] & $\mathrm{RaCe}$ & $\mathrm{NaOCl}$ solution for $5 \mathrm{~min}$ & $\mathrm{NaOCl}$ causes deterioration on the surface of $\mathrm{RaCe}$ \\
\hline Ametrano et al. 2011 [75] & ProTaper & $5.25 \% \mathrm{NaOCl}, 17 \%$ EDTA & $\begin{array}{l}\text { short-term contact between } \mathrm{NaOCl} \text { and EDTA en- } \\
\text { dodontic irrigants and ProTaper instruments caused } \\
\text { alterations in the surface of instruments }\end{array}$ \\
\hline Fayyad and Mahran [76] & $\begin{array}{l}\text { GTX, TF, RaCe and Hero } \\
\text { Shaper }\end{array}$ & $5.25 \% \mathrm{NaOCl}, 17 \%$ EDTA & $\begin{array}{l}17 \% \text { EDTA did not significantly affect the surface } \\
\text { roughness of the instruments, whilst } 5.25 \% \mathrm{NaOCl} \text { in- } \\
\text { creased the surface roughness }\end{array}$ \\
\hline Uslu et al. 2018 [77] & HyFlex EDM, HyFlex CM & $5.25 \% \mathrm{NaOCl}, 17 \%$ EDTA & EDTA increase roughness, $\mathrm{NaOCl}$ not increase \\
\hline
\end{tabular}

Table 10. Characteristic of studies performed with Electrochemical methods. Endodontic instruments were treated with hypochlorite at different concentrations.

\begin{tabular}{|c|c|c|c|}
\hline Autor, data & Means of investigation & Instruments & Results \\
\hline Shahi et al. 2012 [78] & $\begin{array}{l}\text { Electrochemical Impedance } \\
\text { Spectroscopy (EIS) }\end{array}$ & RaCe, Mtwo & $\begin{array}{l}\text { Corrosion resistance was significantly higher in Mtwo } \\
\text { files compared to RaCe files in sizes \#25, \#30, and } \\
\# 35 \text { and these properties might affect clinical efficacy } \\
\text { of these instruments }\end{array}$ \\
\hline Stokes et al. 1999 [79] & $\begin{array}{l}\text { open circuit potential (OCP) } \\
\text { ( } \mathrm{NaClO} 5.25 \% \text { for } 1 \text { Hour) }\end{array}$ & K-Flex, Flex-O, Flex-R, NiTifile & $\begin{array}{l}\text { No significant difference between stainless steel and } \\
\text { NiTi }\end{array}$ \\
\hline Casella et al. 2011 [80] & $\begin{array}{l}\text { saturated calomel electrode } \\
\text { (SCE) } 5 \% \quad \mathrm{NaClO} \text { aerated } \\
\text { solution at } 37 \mathrm{uC}\end{array}$ & GT Rotary, K3, K file & $\begin{array}{l}\text { The sterilisation treatment had no significant influ- } \\
\text { ence on the corrosion resistance (Only k3 decrease } \\
\text { corrosion) }\end{array}$ \\
\hline
\end{tabular}

composed of silicon or silicon nitride, which has a radius of curvature of the order of nanometers. Flexing the detector tip causes it to interact with the sample through van der Waals forces [105].

Three main parameters are taken into consideration when analyzing the surface with AFM: arithmetic mean roughness (AMR), maximum height $(\mathrm{MH})$ and root mean square (RMS).

Data from studies conducted with atomic force microscopy are in agreement with those conducted with SEM. They report a statistically significant increase in surface imperfections after five autoclave cycles. The analyzed studies and their results are shown in Table 6. The corrosive effects of sodium hypochlorite and EDTA were studied using AFM by Uslu et al. [77], Prasad et al. [72], Cai et al.
[71], Saglam et al. [73], Topuz et al. [74], Ametrano et al. [75], Fayyad and Mahran [76] and Can Saglam et al. [70] (Table 9, Ref. [48, 65-77]).

A previous literature review with meta-analysis conducted by our research group [41] was carried out on the surface alterations induced by autoclaving, sodium hypochlorite and EDTA. The AMR and RMS were used as parameters in the AFM analysis of the surface. The results suggest that five autoclave cycles induce statistically significant corrosive phenomena, called micro-pitting, and corrosion occurs after only 5 minutes of hypochlorite exposure and after 10 minutes of EDTA exposure [41].

The scientific literature is in full agreement that both intra-canal disinfectants and autoclave sterilization cause surface alterations. 
Table 11. Characteristics of the studies that relate the cutting efficiency of endodontic instruments in relation to disinfection and sterilization procedures.

\begin{tabular}{|c|c|c|c|}
\hline Author data & Instruments & Method sterilization & Reduction of cutting capacity, expressed as a percentage of the control \\
\hline \multirow[t]{4}{*}{ Schafer et al. 2002 [81] } & Niti Kfile PVD & Autoclave $5-10$ cycles $135^{\circ}$ & No reduction \\
\hline & & NaOC1 5.25\% 30 minutes & No reduction \\
\hline & Niti Kfile & Autoclave $5-10$ cycles & $50.6 \%-16.1 \%$ \\
\hline & & $\mathrm{NaOC} 15.25 \%$ & No reduction \\
\hline \multirow[t]{18}{*}{ Haikel et al. 1996 [82] } & Unifile & Dry hot sterilization $5-10$ cycles $180^{\circ}$ per 2 hours & No reduction (115.9\%-104.9\% efficacy) \\
\hline & & $\mathrm{NaOCl} 2 \% 12-48$ hours & $29.7 \%-36.7 \%$ \\
\hline & & Ultrasonic cleaning 1-4 hours, $\mathrm{NaOC} 1$ (2.5\%) and $\mathrm{NH} 4$ (5\%) & $61.8 \%-61.8 \%$ \\
\hline & & NH4 1-4 hours & $62.6 \%-62.2 \%$ \\
\hline & & Chemiclave $5-20$ cycles per 20 minutes & $63.9 \%-67.1 \%$ \\
\hline & & Glass bed sterilization $10-40$ cycles per 40 seconds at $250^{\circ}$ & $5.4 \%-14.1 \%$ \\
\hline & Flexofile & Dry hot sterilization $5-10$ cycles per 2 hours $180^{\circ}$ & $1.1 \%-1.7 \%$ \\
\hline & & NaOC1 2\% 12-48 hours & $57.9 \%-67.6 \%$ \\
\hline & & Ultrasonic cleaning 1-4 hours NaOC1 (2.5\%) and NH 4 (5\%) & $66.8 \%-65.7 \%$ \\
\hline & & NH4 1-4 hours & $68.5 \%-68.5 \%$ \\
\hline & & Chemiclave 5-20 cycles per 20 minutes & 77\%-73\% \\
\hline & & Glass bed sterilization $10-40$ cycles per 40 seconds at $250^{\circ} \mathrm{C}$ & $67.4 \%-66.9 \%$ \\
\hline & H-File & Dry hot sterilization 5-10 cycles per 2 hours & $49.8 \%-54.1 \%$ \\
\hline & & $\mathrm{NaOCl} 2 \% 12-48$ hours & $66.3 \%-62.9 \%$ \\
\hline & & Ultrasonic cleaning 1-4 hours NaOC1 (2.5\%) and NH 4 (5\%) & $65.3 \%-97.8 \%$ \\
\hline & & NH4 1-4 hours & $50 \%-53.5 \%$ \\
\hline & & Chemiclave 5-20 cycles per 20 minutes & $68.1 \%-50.4 \%$ \\
\hline & & Glass bed sterilization $10-40$ cycles per 40 seconds at $250^{\circ} \mathrm{C}$ & $76 \%-59 \%$ \\
\hline Rapisarda et al. 1999 [31] & ProFile instruments & $7-14$ cycles autoclave & $20 \%-50 \%$ \\
\hline Seago et al. 2015 [83] & Hyflex CM NiTi rotary files & From 1 to 9 sterilization cycles by autoclave after each single use & $\begin{array}{l}\text { no statistical decrease after } 1,4,5 \text {, and } 6 \text { cycles. A statistically significant decrease } \\
\text { in cutting efficiency was for } 2,3,7,8 \text {, and } 9 \text { cycles }\end{array}$ \\
\hline \multirow[t]{4}{*}{ Haikel et al. 1998 [84] } & Niti file Maillefer & 2.5\% NaOCI. $12-48$ hours & (109.8\% efficacy)-24.36\% \\
\hline & Niti file Brasseler & 2.5\% NaOCI. $12-48$ hours & $16.42 \%-32.87 \%$ \\
\hline & Niti file JS Dental & 2.5\% NaOCI. $12-48$ hours & $29.97 \%-25.35 \%$ \\
\hline & Niti file McSpadden & 2.5\% NaOCI. $12-48$ hours & $3.25 \%-$ no reduction \\
\hline \multirow[t]{2}{*}{ Morrison et al. 1989 [85] } & K file & Sterilization after $1,5,10$ use & No statistically significant change compared to the control group \\
\hline & Flexofiles & Sterilization after $1,5,10$ use & No statistically significant change compared to the control group \\
\hline Neal et al. 1983 [86] & K-type, stainless steel files & & $\begin{array}{l}\text { autoclave sterilization resulted in a small but significant decrease in cutting ability } \\
\text { of the files }\end{array}$ \\
\hline
\end{tabular}




\subsubsection{Electrochemical methods}

Shahi et al. [78], Stokes et al. [79] and Casella et al. [80] used electrochemical systems to investigate the effects of hypochlorite on the surfaces of instruments. The specific methods with the results are reported in Table 10 (Ref. [78-80]).

According to these studies, immersion in sodium hypochlorite at concentrations equal to $5.25 \%$ at a temperature of 37 degrees does not cause a significant decrease in corrosion resistance, although both SEM and AFM reveal effects on the investigated surface, as previously reported. If the exposure times exceed 12-24 hours, the corrosive effects will be apparent not only microscopically but also macroscopically.

\subsection{Cutting efficiency}

The first studies conducted on changes in cutting efficiency following sterilization were conducted by Neal et al. in 1983 [86], who described a significant decrease in the cutting capacity of K-files after 10 cycles of autoclaving. Subsequently, these data were partially disproved by Morrison et al. [85], who stated that there was no reduction in the cutting depth after five autoclaving cycles and that decreases were only due to clinical use.

Similar to Morrison, Seago et al. [83] did not observe any statistically significant reductions in the cutting capacity of HyFlex (rotary NiTi instruments) after one or two autoclave cycles.

Rapisarda et al. [31] reported that the cutting capacity of Profile NiTi rotary tools was reduced, with decreases ranging from $20 \%$ for 7 cycles to $50 \%$ for 14 cycles (heat sterilization). Corrosive phenomena were induced by the oxidation of surface layers with the formation of NiTi oxides [31].

The data reported by Schafer et al. [81] and Haikel et al. [82, 84] support a reduction in cutting efficiency. Schafer observed a reduction in the cutting efficiency of Kwires (NiTi) equal to $16.1 \%$ after 5 sterilization cycles and $50.8 \%$ after 10 autoclaving cycles at a temperature of 135 ${ }^{\circ} \mathrm{C}$ [81]. Haikel noted a reduction in cutting efficiency following immersion in $2.5 \%$ sodium hypochlorite for a time ranging from 12 to 48 hours and also reported that the use of ultrasonic trays resulted in a reduction of $20 \%-60 \%$.

The effects of heat sterilization can appear after 5 sterilization cycles, but in most studies, they became evident after 10 cycles [31, 81, 82]. Sodium hypochlorite with concentrations ranging from $2.5 \%$ to $5.25 \%$ for 30 minutes showed no effect on shear capacity, as reported by Schafer et al. [81], but if the duration reached 12-48 hours, corrosive phenomena were triggered, resulting in a net reduction in efficiency [84, 106] (Table 11, Ref. [31, 81-86]).

\section{Conclusions}

The study of the literature shows that there are conflicting findings regarding the different effects of sterilization procedures. In sum, sterilization and disinfection procedures produce changes in physical and mechanical characteristics, but conclusions about whether the effects are favorable or unfavorable for clinical use are not always consistent between studies.

The alterations can be summarized as follows:

- There is a reduction in cutting capacity after autoclaving, and it becomes statistically significant after five autoclaving cycles;

- A corrosive effect is observed after the use of disinfectants based on sodium hypochlorite (12-48 hours) and after the application of heat sterilization;

- There is a potential shape recovery effect with regard to deformation and increased resistance to torsional and cyclic fatigue after sterilization, but not all studies agree.

\section{Author contributions}

Conceptualization, MD, AD, KZ, RA, GI; methodology, MD and DS; software, GI; validation, MD and $\mathrm{AD}$; formal analysis, $\mathrm{MD}$ and $\mathrm{AD}$; investigation, $\mathrm{DS}$ and $\mathrm{AD}$ and VCAC; resources, LLM; data curation, EL, BR and LL; writing-original draft preparation, MD and GT; writing-review and editing, MD, GT, CA and LLM.

\section{Ethics approval and consent to participate}

Not applicable.

\section{Acknowledgment}

Not applicable.

\section{Funding}

This research received no external funding.

\section{Conflict of interest}

The authors declare no conflict of interest.

\section{References}

[1] Ataya M, Ha J, Kwak SW, Abu-Tahun IH, El Abed R, Kim H. Mechanical Properties of Orifice Preflaring Nickel-titanium Rotary Instrument Heat Treated Using T-Wire Technology. Journal of Endodontics. 2018; 44: 1867-1871.

[2] Aydın ZU, Keskin NB, Özyürek T, Geneci F, Ocak M, Çelik HH. Microcomputed Assessment of Transportation, Centering Ratio, Canal Area, and Volume Increase after Single-file Rotary and Reciprocating Glide Path Instrumentation in Curved Root 
Canals: a Laboratory Study. Journal of Endodontics. 2019; 45: 791-796.

[3] Plotino G, Nagendrababu V, Bukiet F, Grande NM, Veettil SK, De-Deus G, et al. Influence of Negotiation, Glide Path, and Preflaring Procedures on Root Canal Shaping-Terminology, Basic Concepts, and a Systematic Review. Journal of Endodontics. 2020; 46: 707-729.

[4] Testarelli L, Putortì E, Staffoli S, Obino FV, Di Nardo D, Miccoli G, et al. Cyclic fatigue of NiTi instruments used in complex curvatures with continuous or reciprocating rotation. Giornale Italiano Di Endodonzia. 2014; 28: 87-90.

[5] Bagg J, Smith AJ, Hurrell D, McHugh S, Irvine G. Presterilisation cleaning of re-usable instruments in general dental practice. British Dental Journal. 2007; 202: E22; discussion $550-551$.

[6] Kumar KV, Kiran Kumar KS, Supreetha S, Raghu KN, Veerabhadrappa AC, Deepthi S. Pathological evaluation for sterilization of routinely used prosthodontic and endodontic instruments. Journal of International Society of Preventive \& Community Dentistry. 2015; 5: 232-236.

[7] Dioguardi M, Sovereto D, Illuzzi G, Laneve E, Raddato B, Arena C, et al. Management of Instrument Sterilization Workflow in Endodontics: a Systematic Review and Meta-Analysis. International Journal of Dentistry. 2020; 2020: 5824369.

[8] Linsuwanont P, Parashos P, Messer HH. Cleaning of rotary nickel-titanium endodontic instruments. International Endodontic Journal. 2004; 37: 19-28.

[9] Head MW, Ritchie D, McLoughlin V, Ironside JW. Investigation of PrPres in dental tissues in variant CJD. British Dental Journal. 2003; 195: 339-343.

[10] Palacios-Sánchez B, Esparza-Gómez GC, Campo-Trapero J, Cerero-Lapiedra R. Implications of prion diseases for dentistry: an update. Oral Surgery, Oral Medicine, Oral Pathology, Oral Radiology, and Endodontics. 2008; 105: 316-320.

[11] Scully C, Smith AJ, Bagg J. CJD: update for dental staff. Dental Update. 2006; 33: 454-460.

[12] Smith A, Dickson M, Aitken J, Bagg J. Contaminated dental instruments. Journal of Hospital Infection. 2002; 51: 233-235.

[13] Walker JT, Dickinson J, Sutton JM, Raven NDH, Marsh PD. Cleanability of dental instruments-implications of residual protein and risks from Creutzfeldt-Jakob disease. British Dental Journal. 2007; 203: 395-401.

[14] Richards D. Decontamination, single-use instruments and vCJD. Evidence-Based Dentistry. 2007; 8: 32-33.

[15] Scully C, Smith AJ, Bagg J. Prions and the human transmissible spongiform encephalopathies. Dental Clinics of North America. 2003; 47: 493-516.

[16] Smith A, Letters S, Lange A, Perrett D, McHugh S, Bagg J. Residual protein levels on reprocessed dental instruments. Journal of Hospital Infection. 2005; 61: 237-241.

[17] Guiroy DC, Shankar SK, Gibbs CJ, Messenheimer JA, Das S, Gajdusek DC. Neuronal degeneration and neurofilament accumulation in the trigeminal ganglia in Creutzfeldt-Jakob disease. Annals of Neurology. 1989; 25: 102-106.

[18] Favia G, Tempesta A, Limongelli L, Crincoli V, Maiorano E. Medication-Related Osteonecrosis of the Jaws: Considerations on a New Antiresorptive Therapy (Denosumab) and Treatment Outcome after a 13-Year Experience. International Journal of Dentistry. 2016; 2016: 1801676.

[19] Taylor DM. Inactivation of transmissible degenerative encephalopathy agents: a review. Veterinary Journal. 2000; 159: $10-17$.

[20] Sonntag D, Peters OA. Effect of prion decontamination protocols on nickel-titanium rotary surfaces. Journal of Endodontics. 2007; 33: 442-446.

[21] Iandolo A, Pantaleo G, Malvano M, Simeone M, Amato M. Nonsurgical management of complex endodontic cases with several periapical lesions: a case series. Giornale Italiano Di Endodonzia. 2016; 30: 101-110.
[22] Iandolo A, Simeone M, Riccitiello F. La preparazione dell'istmo coronale: una procedura fondamentale per un successo a lungo termine. Giornale Italiano Di Endodonzia. 2012; 26: 150-154.

[23] McGuigan MB, Louca C, Duncan HF. Endodontic instrument fracture: causes and prevention. British Dental Journal. 2013, 214: 341-348.

[24] Madarati AA, Watts DC, Qualtrough AJE. Factors contributing to the separation of endodontic files. British Dental Journal. 2008; 204: 241-245.

[25] Zhao D, Shen Y, Peng B, Haapasalo M. Effect of autoclave sterilization on the cyclic fatigue resistance of thermally treated Nickel-Titanium instruments. International Endodontic Journal. 2016; 49: 990-995.

[26] Viana ACD, Gonzalez BM, Buono VTL, Bahia MGA. Influence of sterilization on mechanical properties and fatigue resistance of nickel-titanium rotary endodontic instruments. International Endodontic Journal. 2006; 39: 709-715.

[27] Khabiri M, Ebrahimi M, Saei MR. The Effect of Autoclave Sterilization on Resistance to Cyclic Fatigue of Hero Endodontic File \#642 (6\%) at Two Artificial Curvature. Journal of Dentistry. 2017; 18: 277-281.

[28] Silvaggio J, Hicks ML. Effect of heat sterilization on the torsional properties of rotary nickel-titanium endodontic files. Journal of Endodontics. 1997; 23: 731-734.

[29] Casper RB, Roberts HW, Roberts MD, Himel VT, Bergeron BE. Comparison of autoclaving effects on torsional deformation and fracture resistance of three innovative endodontic file systems. Journal of Endodontics. 2011; 37: 1572-1575.

[30] King JB, Roberts HW, Bergeron BE, Mayerchak MJ. The effect of autoclaving on torsional moment of two nickel-titanium endodontic files. International Endodontic Journal. 2012; 45: 156161.

[31] Rapisarda E, Bonaccorso A, Tripi TR, Condorelli GG. Effect of sterilization on the cutting efficiency of rotary nickel-titanium endodontic files. Oral Surgery, Oral Medicine, Oral Pathology, Oral Radiology, and Endodontics. 1999; 88: 343-347.

[32] Laneve E, Raddato B, Dioguardi M, Di Gioia G, Troiano G, Lo Muzio L. Sterilisation in Dentistry: a Review of the Literature. International Journal of Dentistry. 2019; 2019: 6507286.

[33] Plotino G, Grande NM, Cordaro M, Testarelli L, Gambarini G. A review of cyclic fatigue testing of nickel-titanium rotary instruments. Journal of Endodontics. 2009; 35: 1469-1476.

[34] Tabassum S, Zafar K, Umer F. Nickel-Titanium Rotary File Systems: What's New? European Endodontic Journal. 2019; 4 111-117.

[35] Khabadze Z, Mordanov O, Balashova M, Stolov L, Pangratyan A, Bokova R, et al. Laboratory Rational of Changes in the Crystal Lattice of Nickel-Titanium Endodontic Rotary Files in Autoclaving. International Journal of Dentistry. 2020; 2020: 8386215.

[36] Zupanc J, Vahdat-Pajouh N, Schäfer E. New thermomechanically treated $\mathrm{NiTi}$ alloys - a review. International Endodontic Journal. 2018; 51: 1088-1103.

[37] Vinothkumar T, Rajadurai A, Kandaswamy D, Prabhakaran G. Microstructure of cryogenically treated martensitic shape memory nickel-titanium alloy. Journal of Conservative Dentistry. 2015; 18: 292-296.

[38] Gil J, Rupérez E, Velasco E, Aparicio C, Manero JM. Mechanism of fracture of NiTi superelastic endodontic rotary instruments. Journal of Materials Science Materials in Medicine. 2018; 29: 131.

[39] Aminsobhani M, Khalatbari MS, Meraji N, Ghorbanzadeh A Sadri E. Evaluation of the Fractured Surface of Five Endodontic Rotary Instruments: a Metallurgical Study. Iranian Endodontic Journal. 2016; 11: 286-292.

[40] Dioguardi M, Sovereto D, Aiuto R, Laino L, Illuzzi G, Laneve E, et al. Effects of Hot Sterilization on Torsional Properties of Endodontic Instruments: Systematic Review with Meta-Analysis. Materials. 2019; 12: 2190. 
[41] Dioguardi M, Crincoli V, Laino L, Alovisi M, Laneve E, Sovereto D, et al. Surface alterations induced on endodontic instruments by sterilization processes, analyzed with atomic force microscopy: A systematic review. Applied Sciences. 2019; 9: 4948

[42] Liberati A, Altman DG, Tetzlaff J, Mulrow C, Gotzsche PC, Ioannidis JP, et al. The PRISMA statement for reporting systematic reviews and meta-analyses of studies that evaluate health care interventions: explanation and elaboration. PLOS Medicine. 2009; 6: e1000100.

[43] Moher D, Liberati A, Tetzlaff J, Altman DG, Group P. Preferred reporting items for systematic reviews and meta-analyses: the PRISMA statement. PLOS Medicine. 2009; 6: e1000097.

[44] Arias A, Perez-Higueras JJ, de la Macorra JC. Influence of clinical usage of GT and GTX files on cyclic fatigue resistance. International Endodontic Journal. 2014; 47: 257-263.

[45] Plotino G, Costanzo A, Grande NM, Petrovic R, Testarelli L, Gambarini G. Experimental Evaluation on the Influence of Autoclave Sterilization on the Cyclic Fatigue of New NickelTitanium Rotary Instruments. Journal of Endodontics. 2012; 38: 222-225.

[46] Mize SB, Clement DJ, Pruett JP, Carnes DL. Effect of sterilization on cyclic fatigue of rotary nickel-titanium endodontic instruments. Journal of Endodontics. 1998; 24: 843-847.

[47] Sharroufna R, Mashyakhy M. The Effect of Multiple Autoclave Sterilization on the Cyclic Fatigue of Three Heat-Treated Nickel-Titanium Rotary Files: EdgeFile X7, Vortex Blue, and TRUShape. BioMed Research International. 2020; 2020: 8826069.

[48] Das P, Swapna D, Nadig R. Comparison and evaluation of surface deformation of Hyflex controlled memory and Hyflex electric discharge machining nickel titanium rotary files and cyclic fatigue resistance after instrumentation and heat sterilization an in vitro study. Journal of Conservative Dentistry. 2019; 22: 464-469.

[49] Alshwaimi E. Effect of sterilization on cyclic fatigue resistance of Proflexendo endodontic rotary files. Saudi Journal of Medicine and Medical Sciences. 2019; 7: 151-155.

[50] Arias A, Macorra JC, Govindjee S, Peters OA. Effect of gammaray sterilization on phase transformation behavior and fatigue resistance of contemporary nickel-titanium instruments. Clinical Oral Investigations. 2020; 24: 3113-3120.

[51] Kim W, Oh S, Ryu G, Kim T, Kim S, Kim D, et al. Effect of autoclave sterilization on cyclic fatigue and torsional fracture resistance of NiTi rotary instruments. Odontology. 2020; 108: 194-201.

[52] Li X, Zheng P, Xu L, Su Q. The influence of autoclave sterilization on surface characteristics and cyclic fatigue resistance of 3 nickel-titanium rotary instruments. Shanghai Kou Qiang Yi Xue. 2016; 24: 690-695. (In Chinese)

[53] Yang YJ, Hou BX, Hou XM. Effect of autoclave on surface microstructure and cyclic fatigue resistance of R-phase rotary instruments. Beijing da xue xue bao Yi xue ban. 2018; 50: 882886. (In Chinese)

[54] Pedullà E, Grande NM, Plotino G, Pappalardo A, Rapisarda E. Cyclic fatigue resistance of three different nickel-titanium instruments after immersion in sodium hypochlorite. Journal of Endodontics. 2011; 37: 1139-1142.

[55] Bulem ÜK, Kececi AD, Guldas HE. Experimental evaluation of cyclic fatigue resistance of four different nickel-titanium instruments after immersion in sodium hypochlorite and/or sterilization. Journal of Applied Oral Science. 2013; 21: 505-510.

[56] Özyürek T, Yılmaz K, Uslu G. The effects of autoclave sterilization on the cyclic fatigue resistance of ProTaper Universal, ProTaper next, and ProTaper Gold nickel-titanium instruments. Restorative Dentistry \& Endodontics. 2017; 42: 301-308.

[57] Iverson GW, von Fraunhofer JA, Hermann JW. The effects of various sterilization methods on the torsional strength of endodontic files. Journal of Endodontics. 1985; 11: 266-268.
[58] Chenail BL, Brantley WA, Gerstein H. Clockwise torsional properties of new and used root canal files. Journal of Endodontics. 1986; 12: 59-63.

[59] Hilt BR, Cunningham CJ, Shen C, Richards N. Torsional properties of stainless-steel and nickel-titanium files after multiple autoclave sterilizations. Journal of Endodontics. 2000; 26: 76 80.

[60] Canalda-Sahli C, Brau-Aguadé E, Sentís-Vilalta J. The effect of sterilization on bending and torsional properties of K-files manufactured with different metallic alloys. International Endodontic Journal. 1998; 31: 48-52.

[61] Razavian H, Iranmanesh P, Mojtahedi H, Nazeri R. Effect of Autoclave Cycles on Surface Characteristics of S-File Evaluated by Scanning Electron Microscopy. Iranian Endodontic Journal. 2016; 11: 29-32.

[62] Alexandrou G, Chrissafis K, Vasiliadis L, Pavlidou E, Polychroniadis EK. Effect of heat sterilization on surface characteristics and microstructure of Mani NRT rotary nickel-titanium instruments. International Endodontic Journal. 2006; 39: 770-778.

[63] Qaed N, Mourshed B, Al-Shamiri H, Alaizari N, Alhamdah S. The Effect of surface topographical changes of two different surface treatments rotary instrument. Journal of Clinical and Experimental Dentistry. 2018; 10: e49-e53.

[64] Alexandrou GB, Chrissafis K, Vasiliadis LP, Pavlidou E, Polychroniadis EK. SEM observations and differential scanning calorimetric studies of new and sterilized nickel-titanium rotary endodontic instruments. Journal of Endodontics. 2006; 32: 675679.

[65] Yılmaz K, Uslu G, Özyürek T. Effect of multiple autoclave cycles on the surface roughness of HyFlex CM and HyFlex EDM files: an atomic force microscopy study. Clinical Oral Investigations. 2018; 22: 2975-2980.

[66] Nair AS, Tilakchand M, Naik BD. The effect of multiple autoclave cycles on the surface of rotary nickel-titanium endodontic files: an in vitro atomic force microscopy investigation. Journal of Conservative Dentistry. 2015; 18: 218-222.

[67] Valois CRA, Silva LP, Azevedo RB. Multiple autoclave cycles affect the surface of rotary nickel-titanium files: an atomic force microscopy study. Journal of Endodontics. 2008; 34: 859-862.

[68] Spagnuolo G, Ametrano G, D’Antò V, Rengo C, Simeone M, Riccitiello F, et al. Effect of autoclaving on the surfaces of TiN -coated and conventional nickel-titanium rotary instruments. International Endodontic Journal. 2012; 45: 1148-1155.

[69] Inan U, Aydin C, Uzun O, Topuz O, Alacam T. Evaluation of the surface characteristics of used and new ProTaper Instruments: an atomic force microscopy study. Journal of Endodontics. 2007; 33: 1334-1337.

[70] Can Sağlam B, Görgül G. Evaluation of surface alterations in different retreatment nickel-titanium files: AFM and SEM study. Microscopy Research and Technique. 2015; 78: 356-362.

[71] Cai J, Tang X, Ge J. Effect of irrigation on surface roughness and fatigue resistance of controlled memory wire nickel-titanium instruments. International Endodontic Journal. 2017; 50: 718724.

[72] Prasad P, Sam J, Kumar A, Kannan. The effect of 5\% sodium hypochlorite, 17\% EDTA and triphala on two different rotary Ni-Ti instruments: an AFM and EDS analysis. Journal of Conservative Dentistry. 2014; 17: 462-466.

[73] Sağlam BC, Koçak S, Koçak MM, Topuz O. Effects of irrigation solutions on the surface of ProTaper instruments: a microscopy study. Microscopy Research and Technique. 2012; 75: 15341538.

[74] Topuz O, Aydin C, Uzun O, Inan U, Alacam T, Tunca YM. Structural effects of sodium hypochlorite solution on RaCe rotary nickel-titanium instruments: an atomic force microscopy study. Oral Surgery, Oral Medicine, Oral Pathology, Oral Radiology, and Endodontics. 2008; 105: 661-665.

[75] Ametrano G, D’Antò V, Di Caprio MP, Simeone M, Rengo S, Spagnuolo G. Effects of sodium hypochlorite and ethylenedi- 
aminetetraacetic acid on rotary nickel-titanium instruments evaluated using atomic force microscopy. International Endodontic Journal. 2011; 44: 203-209.

[76] Fayyad DM, Mahran AH. Atomic force microscopic evaluation of nanostructure alterations of rotary NiTi instruments after immersion in irrigating solutions. International Endodontic Journal. 2014; 47: 567-573.

[77] Uslu G, Özyürek T, Yılmaz K. Effect of Sodium Hypochlorite and EDTA on Surface Roughness of HyFlex CM and HyFlex EDM Files. Microscopy Research and Technique. 2018; 81: 1406-1411.

[78] Shahi S, Mokhtari H, Rahimi S, Shiezadeh V, Ashasi H, Abdolrahimi $\mathrm{M}$, et al. Electrochemical corrosion assessment of RaCe and Mtwo rotary nickle-titanium instruments after clinical use and sterilization. Medicina Oral, Patologia Oral Y Cirugia Bucal. 2012; 17: e331-e336.

[79] Stokes OW, Di Fiore PM, Barss JT, Koerber A, Gilbert JL, Lautenschlager EP. Corrosion in stainless-steel and nickel-titanium files. Journal of Endodontics. 1999; 25: 17-20.

[80] Casella G, Rosalbino F. Corrosion behaviour of NiTi endodontic instrument. Corrosion Engineering, Science and Technology. 2011; 46: 521-523.

[81] Schafer E. Effect of sterilization on the cutting efficiency of PVD-coated nickel-titanium endodontic instruments. International Endodontic Journal. 2002; 35: 867-872.

[82] Haïkel Y, Serfaty R, Bleicher P, Lwin TT, Allemann C. Effects of cleaning, disinfection, and sterilization procedures on the cutting efficiency of endodontic files. Journal of Endodontics. 1996; 22: 657-661.

[83] Seago ST, Bergeron BE, Kirkpatrick TC, Roberts MD, Roberts HW, Himel VT, et al. Effect of repeated simulated clinical use and sterilization on the cutting efficiency and flexibility of Hyflex CM nickel-titanium rotary files. Journal of Endodontics. 2015; 41: 725-728.

[84] Haïkel Y, Serfaty R, Wilson P, Speisser JM, Allemann C. Cutting efficiency of nickel-titanium endodontic instruments and the effect of sodium hypochlorite treatment. Journal of Endodontics. 1998; 24: 736-739.

[85] Morrison SW, Newton CW, Brown CE. The effects of steam sterilization and usage on cutting efficiency of endodontic instruments. Journal of Endodontics. 1989; 15: 427-431.

[86] Neal RG, Craig RG, Powers JM. Effect of sterilization and irrigants on the cutting ability of stainless steel files. Journal of Endodontics. 1983; 9: 93-96.

[87] Silva EJNL, Zanon M, Hecksher F, Belladonna FG, de Vasconcelos RA, Fidalgo TKdS. Influence of autoclave sterilization procedures on the cyclic fatigue resistance of heat-treated nickeltitanium instruments: a systematic review. Restorative Dentistry \& Endodontics. 2020; 45: e25.

[88] Dioguardi M, Laneve E, Di Cosola M, Cazzolla AP, Sovereto D, Aiuto R, et al. The effects of sterilization procedures on the cutting efficiency of endodontic instruments: A systematic review and network meta-analysis. Materials. 2021; 14: 1559.

[89] Jena D, Dash S, Jena SP, Singh NR, Kumari S. Sterilization in endodontics: A newer concept. Indian Journal of Forensic Medicine and Toxicology. 2020; 14: 8356-8359.

[90] Rajpurohit GK, Chowdary A. Effect of autoclave sterilization on the physical properties of nickel-titanium rotary files - A review literature. Drug Invention Today. 2019; 11: 322-324.

[91] Seto BG, Nicholls JI, Harrington GW. Torsional properties of twisted and machined endodontic files. Journal of Endodontics. 1990; 16: 355-360.

[92] Larsen CM, Watanabe I, Glickman GN, He J. Cyclic fatigue analysis of a new generation of nickel titanium rotary instruments. Journal of Endodontics. 2009; 35: 401-403.

[93] Dioguardi M, Troiano G, Laino L, Lo Russo L, Giannatempo $\mathrm{G}$, Lauritano F, et al. ProTaper and WaveOne systems threedimensional comparison of device parameters after the shaping technique. a micro-CT study on simulated root canals. Interna- tional Journal of Clinical and Experimental Medicine. 2015; 8 : 17830-17834.

[94] Lopreite G, Basilaki J, Hecht P. Influence of cyclical fatigue on torsional fracture morphology in endodontic instruments. Acta Odontologica Latinoamericana. 2013; 26: 32-36.

[95] Troiano G, Dioguardi M, Cocco A, Giannatempo G, Laino L, Ciavarella D, et al. Influence of Operator's Experience on the Shaping Ability of Protaper Universal and Waveone Systems: a Comparative Study on Simulated Root Canals. Open Dentistry Journal. 2016; 10: 546-552.

[96] Alcalde MP, Duarte MAH, Bramante CM, de Vasconselos BC, Tanomaru-Filho M, Guerreiro-Tanomaru JM, et al. Cyclic fatigue and torsional strength of three different thermally treated reciprocating nickel-titanium instruments. Clinical Oral Investigations. 2018; 22: 1865-1871.

[97] Del Fabbro M, Afrashtehfar KI, Corbella S, El-Kabbaney A, Perondi I, Taschieri S. In Vivo and in Vitro Effectiveness of Rotary Nickel-Titanium vs Manual Stainless Steel Instruments for Root Canal Therapy: Systematic Review and Meta-analysis. Journal of Evidence-Based Dental Practice. 2018; 18: 59-69.

[98] Camps JJ, Pertot WJ. Relationship between file size and stiffness of stainless steel instruments. Endodontics \& Dental Traumatology. 1994; 10: 260-263.

[99] Alfoqom Alazemi M, Bryant ST, Dummer PMH. Deformation of HyFlex CM instruments and their shape recovery following heat sterilization. International Endodontic Journal. 2015; 48: 593-601.

[100] Testarelli L, Gallottini L, Gambarini G. Mechanical properties of nickel-titanium files following multiple heat sterilizations. Minerva Stomatol. 2003; 52: 169-173. (In Italian)

[101] Haïkel Y, Serfaty R, Bleicher P, Lwin TT, Allemann C. Effects of cleaning, chemical disinfection, and sterilization procedures on the mechanical properties of endodontic instruments. Journal of Endodontics. 1997; 23: 15-18.

[102] Berutti E, Angelini E, Rigolone M, Migliaretti G, Pasqualini D. Influence of sodium hypochlorite on fracture properties and corrosion of ProTaper Rotary instruments. International Endodontic Journal. 2006; 39: 693-699.

[103] Han-Hsing Lin J, Karabucak B, Lee S. Effect of sodium hypochlorite on conventional and heat-treated nickel-titanium endodontic rotary instruments - an in vitro study. Journal of Dental Sciences. 2021; 16: 738-743.

[104] Grimsdottir MR, Gjerdet NR, Hensten-Pettersen A. Composition and in vitro corrosion of orthodontic appliances. American Journal of Orthodontics and Dentofacial Orthopedics. 1992; 101: 525-532.

[105] Binnig, Quate, Gerber. Atomic force microscope. Physical Review Letters. 1986; 56: 930-933.

[106] Crincoli V, Scivetti M, Di Bisceglie MB, Pilolli GP, Favia G. Unusual case of adverse reaction in the use of sodium hypochlorite during endodontic treatment: a case report. Quintessence International. 2008; 39: e70-e73.

Abbreviations: PRISMA, Preferred Reporting Items for Systematic reviews and Meta-Analyses; SEM, scanning electron microscopy; AFM, atomic force microscopy; AMR, arithmetic mean roughness; $\mathrm{MH}$, maximum height; RMS, root mean square.

Keywords: Cyclic fatigue; Endodontics; NiTi alloy; Endodontic instruments; Torsional resistance; Flexural fatigue; Corrosion; Cutting efficiency; Mechanical property; Fatigue properties

Send correspondence to: Mario Dioguardi, Department of Clinical and Experimental Medicine, University of Foggia, 71122 Foggia, Italy, E-mail: mario.dioguardi@unifg.it 